\title{
The Regulation of Third Party Campaigning in UK Elections
}

\author{
JACOB ROWBOTTOM
}

\begin{abstract}
This article looks at the regulation of third parties in UK election law. During the 2019 general election campaign, media reports noted an increase in non-party organisations spending money on electoral advertisements on social media. Such advertisements raised a number of ethical questions, related to spending, transparency, and the content of the messages. Despite such recent concerns, third party electoral activity in the UK is not new, and the existing legal framework regulates campaign spending. That framework has its roots in Victorian-era election law and has been periodically updated. This article will look at the challenges in designing laws to regulate third party electoral activity, as a difficult line has to be drawn to ensure the laws are effective, while at the same time not imposing too many burdens on independent political activity. Moreover, the move to digital campaigning poses some further challenges, such as monitoring compliance by third party campaigners. While there are no simple solutions to some of the issues raised by third party electoral activity, this article will note some of the measures that could at least improve the transparency of such campaigning.
\end{abstract}

Keywords: campaign finance, third parties, election campaigns, social media, election law, transparency

PRIOR TO THE 2019 general election, UK election law had been deemed by a number of reviewing bodies as 'not fit for purpose' and not doing enough to regulate digital campaigning. The electoral system was thought to be vulnerable to anonymous campaign messages, foreign interference and various forms of manipulation. Despite such concerns, the law remained unchanged, and the 2019 election was conducted under a legal framework regarded by many to be out of date. During the 2019 campaign, a number of concerns about third party activity were expressed, such as the rise of 'shadow campaigns' that spent money on electoral advertising on social media platforms. ${ }^{1}$ Such advertisements were purchased by some third parties that did not have an existing public profile, and often had names that gave little indication of the advertiser's ideological position. Whether or not the advertisements were effective, such practices raised legitimate concerns about the lack of transparency and how it could provide a cover for unethical conduct.
Contrary to popular perceptions, digital campaigning is not unregulated. The existing rules regulating election spending by third parties apply to online communications. Many third parties engaging in digital campaigning are registered with the Electoral Commission. In 2019, the register included not just familiar names such as Hope Not Hate and 38 Degrees, but also included some less well-known groups, with names such as Capitalist Worker, Working 4 UK, Parents' Choice, Scientists for EU, and Right to Rent, Right to Buy, Right to Own. Spending on election advertising by registered third parties is also disclosed to the regulator. In its report on the 2015 campaign, the Electoral Commission noted that third parties spent a total of $£ 30,566$ with Facebook. ${ }^{2}$ Given the regulations apply to digital campaigns, it begs the question of why the law is regarded as 'unfit for purpose' and in what way it should be changed.

To put these questions into context, the discussion will examine the development of 
third party campaign regulation, and identify some of the problems that have emerged. While third party activity can provide a valuable channel for participation outside of political parties, such activity can also provide a route for avoiding the rules applicable to parties and candidates. For this reason, regulating third parties requires a difficult balance to be struck, which the Neill Committee described as the most difficult problem' for campaign spending laws. ${ }^{3}$ The discussion will not attempt to evaluate the extent of third party activity in the UK or the levels of spending. Instead, it will consider the robustness of the regulatory framework in the light of developing campaign techniques.

\section{The rationales for regulating third parties}

The term third party is used here to describe people or institutions that are engaged in election campaigning, but are not political parties or candidates. There are a number of reasons why the regulation of third party electoral activity is important. The first is concerned with the problem of avoidance of the campaign conduct rules applicable to candidates and parties. Limits on the amounts that parties and candidates can spend would have little effect if political money could simply be routed to non-party actors to engage in electoral advocacy. Similarly, requirements on the transparency of donations to political parties would be ineffective if money could be donated to third parties without disclosure. Under this line of argument, laws regulating third party spending play a supporting role to the primary controls on parties and candidates. Such concerns about avoidance are invoked in the terminology of 'shadow' campaigns, which paints a picture of organisations engaging in parallel electoral activities seemingly on behalf of a candidate or party, without being subject to the same constraints. If this line of thought is followed, then law makers will start by making rules for political parties, and then devise analogous rules to be applied to third parties.

In addition to the anti-avoidance arguments, there are free-standing reasons for regulating third parties. If the goal of election finance laws is to stop inequalities in wealth generating an advantage in the political process, then that rationale applies with equal force to wealth routed through third parties. According to this view, high spending by a wealthy person or organisation in an election can undermine political equality. Similarly, if the public needs to be aware of who is behind a message and paying for it, to help assess the content of the message, then transparency will be required (and may be more necessary) in relation to third party messages. Under this line of argument, there are direct reasons for regulating third parties that are not just about making the controls on parties and candidates workable or to prevent avoidance of the rules. Such direct reasons are likely to receive greater attention if third parties play a larger role in future elections.

\section{Third parties and UK election law}

UK election finance laws have their origins in a statutory framework first enacted in 1883. The Victorian legislation imposed spending limits on candidates during the formal election period. The limit was designed to prevent candidates being under pressure to spend large sums on a growing electorate and corruptly reward voters, and also to provide a degree of fairness between candidates. Once those rules were in place, it soon became clear that third parties were contravening the spirit of the law. MPs complained of organised interests spending large sums and sending people to campaign in constituencies without being subject to the restraints imposed on candidates. The Representation of the People Act 1918 amended the framework by providing a complete bar on third party spending on public meetings, adverts or publications in support of candidates, unless those expenses were authorised by the election agent (and thereby to count against the candidate's spending limit). The framework was further extended in 1949 to cover any spending in support of a candidate by presenting the candidate, his views, or 'his backing or disparaging another candidate'. However, that amendment permitted third party spending within a limit of 10 
shillings. The legal framework therefore envisaged a limited role for third party campaigners. Most campaign activity in support of a candidate was to be channelled through campaign agents, and the rights of others to engage in electoral activity was subordinated to the need to prevent the avoidance of the candidate spending limits.

That framework raised a number of problems. The first concerned the compatibility with freedom of expression. The spending limit was periodically increased, but remained at a low level. By 1992, third parties were permitted to spend only $£ 5$ on campaigning in support of candidates. In 1998, the European Court of Human Rights in Bowman $v U K$ found the provision to violate the right to freedom of expression under Article 10 of the European Convention on Human Rights (ECHR), as such a low limit operated as 'a total barrier' to publishing information to influence the electorate 'during the critical period when their minds were focused on their choice of representative'. ${ }^{4}$ According to the court, some level of third party advocacy must be permitted as an element of free speech. The ruling did not preclude a spending limit set at a higher level, which would allow for some spending on publications and not act as a total barrier. Following the decision in Bowman, the spending limit for third parties in relation to parliamentary elections was increased to $£ 500$, and the statute has been further amended so the limit is now $£ 700$.

A further problem concerned the scope of the old laws. Under the landmark decision in Tronoh Mines, which concerned an electoral advertisement placed by a third party, the statutory limits applied only to spending to support a particular candidate in a particular constituency. ${ }^{5}$ As a result, it did not apply to 'general political propaganda' in support of political parties, even if it had an incidental benefit for certain candidates. That interpretation of the law meant that both political parties and third parties were free to spend without restraint on general party supporting election material. That proved to be one of the biggest gaps in the framework for campaign finance law in the UK, as the law failed to control the biggest area of campaign spending.
The Tronoh Mines decision meant that the election laws in the second half of the twentieth century were outdated. The biggest constraint on third party activity at the national level was the ban on political advertising on the broadcast media. That meant that third parties simply did not have the opportunity to spend money on the 'spot' advertisements seen in the USA. While there was no legal cap on the amounts that could be spent on a campaign in support of a party, there was not as much for third parties to spend money on. The ban on advertising on the broadcast media remains in place, but there is nothing to stop third parties (or political parties) spending money on audiovisual adverts online. The move to campaigning on digital media could, therefore, increase the demand for political money by providing more avenues for parties and third parties to spend money on political advertising.

\section{The Political Parties, Elections and Referendums Act 2000}

After reviewing the funding of political parties in 1998, the Committee on Standards in Public Life recommended an overhaul of the law, including limits on the amounts that can be spent in support of a political party. To make such restrictions workable - and in line with the anti-avoidance rationale-the committee found that third party limits would be required. Following those recommendations, the Political Parties, Elections and Referendums Act 2000 (PPERA) created a regulatory regime in which third parties spending above a threshold sum are required to register with the Electoral Commission. (The threshold is $£ 20,000$ for spending in England, and $£ 10,000$ in Scotland, Wales, and Northern Ireland.) A registered third party can only accept donations from permissible donors, and must disclose donations over a specified threshold that are given to fund campaign activity. Finally, registered third parties are subject to a spending limit in the twelve months prior to a general election. In the 2019 general election, political parties with candidates in 650 constituencies could spend up to $£ 19$ million in the regulated period, while registered third parties 
could spend a maximum of $£ 390,000$ for a UK-wide campaign. ${ }^{6}$ That permits a significant level of third party activity, but also reflects the view that political parties are the primary participants in election campaigns, and that most campaign spending should be channelled through parties.

The regime under the PPERA was built on top of, but did not replace, the pre-existing controls on candidates and those spending in support of candidates. That introduced a level of complexity by establishing a dual system of electoral regulation, with specific restrictions on spending in support of candidates at the local level (primarily enforced by the police) and limits on general campaign spending in support of political parties and categories of candidates (primarily enforced by the Electoral Commission). This means that for third parties, the controls on spending in support of candidates in constituencies are limited to a low level (£700) in the weeks prior to an election. By contrast, third parties are permitted to spend a higher amount in support of a party in the twelve months prior to the polling day.

To add to the complexity, the framework was amended in 2014 to introduce new categories of spending limit. The first new limit applies to 'targeted spending', which is defined as spending that can reasonably be regarded as 'intended to benefit' a party or any of its candidates and 'not intended to benefit any other registered party or any of its candidates'. That means that third party spending in support of a specific political party must either be authorised by the political party in question (and thereby count against the party's spending limit) or be subject to a much lower spending limit. In 2019, targeted spending was subject to a maximum of $£ 39,000$ throughout the UK. ${ }^{7}$ The rationale for the limit is to prevent the avoidance of party spending controls. However, it is not clear why such an amendment was necessary, as such third party spending was already regulated by the existing limits (up to the $£ 390,000$ maximum).

The 2014 amendments also imposed lower limits for spending that is wholly or substantially confined to a particular constituency or number of constituencies. That limit means that in the twelve months prior to a general election, a third party can spend up to
$£ 9,750$ in a particular constituency in support of a particular party. The rationale is to prevent third parties spending large sums in specific constituencies, for example to target key marginals or vulnerable seats. In its review of third party spending limits, the Hodgson Report noted the complexity of having both the longstanding rules on candidate-supporting spending and the constituency level party-supporting spending controls in place, and called for greater alignment of the two regimes. ${ }^{8}$ That complexity can raise problems in terms of the burden imposed on smaller campaigns to ensure compliance, and also poses a challenge for regulators to determine how campaign activity should be split across the two regulatory regimes. The Hodgson Report also noted the difficulties in determining whether digital advertising is focussed on voters in a particular constituency, as a digital advertisement may have a less obvious connection to a physical location than a billboard poster or leaflet. ${ }^{9}$

The 2014 amendments were viewed with suspicion by many, with a perception that the new categories of spending limit aimed to curb the campaigning activities of trade unions and civil society groups that wished to challenge the coalition government's policies. For the 2019 election, only seven organisations sought authorisation from a party to spend over the targeted spending limit, of which six were trade unions. The suspicion was also fuelled by the way the amendments were enacted, without the fact-finding and consultation procedures usually found with election finance laws. As a result, the law was (and continues to be) labelled by critics as the 'gagging Act'. Whatever the merits of those criticisms, it highlights the risk that political finance regulations can be used (or be perceived to be used) to generate an unfair political advantage and entrench power.

The discussion so far has shown how the law has been subject to piecemeal amendments. To recap, there is a dual system of regulation with separate limits applying to activities in support of candidates at the local level, and to general campaigns in support of parties and categories of candidate. There are also various separate spending limits in relation to third party campaigns in support of political parties: 
- The overall spending limit on election campaigning (up to $£ 390,000$ for a campaign across the UK).

- The limit on 'targeted spending' to benefit a particular political party $(£ 39,000)$.

- The limit on spending that is focused on a particular constituency $(£ 9,750)$.

The framework generates a level of complexity for third parties, and for the regulatory bodies seeking to monitor compliance.

A final point on the legal framework is that an exemption from the controls is provided for newspapers and broadcasters. While the exemption is included to protect media freedom, it has allowed newspapers to run highly partisan advocacy during election campaigns. That provision preserves the power of the press to use resources in a way that is not open to other third party campaigners. There have always been questions about the definition of a newspaper for the purposes of the exemption. For example, in some cases in the last century a newspaper would produce a special election edition. However, as more campaigning moves online, the scope of the exemption may well be tested to determine which online publishers produce the equivalent of a newspaper.

While at face value the controls appear to be broad, information released by the Electoral Commission does not show widespread third party spending falling within the regulations. In the 2001 general election, there were only ten third parties registered with the Electoral Commission and for the 2005 general election, twenty-five registered organisations spent over the threshold for registration. In the 2010 general election, thirty-three registered third parties spent over the threshold. Commenting on the 2010 election, the Kelly Committee noted that spending 'by registered third parties forms a relatively small part of overall campaign spending' at just $£ 2.8$ million. ${ }^{10}$ For the 2015 general election, twentythree of the registered organisations spent above the registration threshold and in 2017, eighteen registered third parties spent over the threshold. ${ }^{11}$ However, of those registered, some do spend significant sums. For example, in 2017, the campaign group Best for Britain spent $£ 353,118$ on electoral activities, which exceeded the campaign expenditure of the
Green Party in the same election. The National Union of Teachers spent $£ 326,306$ and the trade union Unite spent over $£ 200,000$ in that election. At the 2019 general election, sixtyone third parties registered with the Electoral Commission (though not all spent over the registration threshold). ${ }^{12}$ From this, it is clear that while there are not lots of third parties reporting a spend above the threshold for registration, some third parties do spend large amounts of money on campaign activities.

The full figures for the 2019 general election will be published later in 2020 and are not available at the time of writing. However, the official statistics on registered campaigners released so far do not paint a picture of the proliferation of high spending 'shadow campaigns'. That does not mean such third party activity is not taking place. Given the potential scale of electoral activity on the digital media, there are significant challenges in determining levels of compliance. An obvious point is that the regulator needs sufficient powers to ensure that the existing law is properly monitored and enforced. Proposals include giving the Electoral Commission powers to obtain information from the digital platforms. While such information would be of great assistance, there would also need to be safeguards in place to protect user privacy and provide a clear procedure for such information requests. Another common proposal is to increase the sanctions available, so that election spending laws have a stronger deterrent effect. However, it is important to note that the figures held by the Electoral Commission do not purport to capture all third party activity. The Electoral Commission regulates only those activities falling within the scope of the regulatory regime, which is limited to spending on defined electoral activities above a specified threshold. The discussion below will consider those limits on the scope of the controls to assess whether there are weak points or deficiencies in the framework (or whether the law is working satisfactorily).

\section{The scope of the controls}

The third party controls do not apply to all political spending that could influence an election, but only to spending on electoral 
activities. In any system of election finance, the way regulated electoral activity is defined will provide a possible route for avoidance. There is a risk that third parties will tailor activities to fall outside the legal definition of an election campaign. As the experience in other jurisdictions has shown, if only overt electoral advocacy were to count as regulated campaign activity, then third parties could engage in phony issue adverts.

If there is a risk of avoidance, then an obvious reaction will be to extend the definition of electoral activity. There are, however, limits to how far regulations can be extended without impinging on general political activities. Unlike general political debate, an election is a formal process that connects the public with the institutions of the state, by transmitting preferences about the composition of the legislature and legitimating a policy programme. As such, an election is structured around choices between parties and candidates, and takes place within a particular time frame. That structure provides the basis for devising the rules that allocate political resources. For these reasons, elections are subject to special considerations. If the definition of electoral activity is too wide, then it may interfere with the more informal and unstructured sphere of general politics. Such concerns are reflected in criticisms that the 2014 amendments to the law 'gagged' charities and civil society organisations. $^{13}$

Even with a wide definition of campaign activity, there will still be the possibility of political money being routed to think tanks or research organisations, that do not engage in electoral advocacy, but which can shape the political agenda and the understanding of issues discussed in an election. That is a real concern, but the solution lies outside election law. Different types of regulation may be more appropriate to promote transparency and limit the influence of wealth in the general political sphere. For example, specialised regulations of lobbying can apply outside an electoral period. Similarly, restrictions on political advertising on the broadcast media are applied at all times and are not limited to elections. These approaches allow for a level of transparency and limitation on political money, without subjecting more general political activities to the stricter spending and disclosure rules found in election laws.

UK law attempts to avoid these problems by taking a flexible definition of campaign activity. Under the PPERA, third party spending is regulated where it can 'reasonably be regarded as intended to promote or procure electoral success at any relevant election' for 'one or more particular registered parties'. ${ }^{14}$ Under that test, there is no bright line or magic formula of words that will bring certain activity into the regulated campaign. The case studies published by the Electoral Commission show how the regulator takes a context-sensitive approach when applying the test. The regulator will consider a range of factors, such as how the content of the material or publication relates to an organisation's past activities, whether the message relates to an issue with a high profile in the election, and whether any information is presented in a way that would lead voters to cast the ballot for or against a party. For example, a third party may publish a message asking voters to email candidates to endorse a particular policy. If that policy could credibly be adopted by any candidate and is not associated with a particular party, then that might fall outside the regulations insofar as it aims to persuade politicians rather than voters. By contrast, if such a communication refers to a policy associated with a particular party, then it may be viewed as an attempt to persuade voters on the merits of that party's position. Such a context-sensitive approach may leave much to the judgment of the regulator and be harder to predict, but is less likely to leave loopholes in the definition.

The third party digital advertisements that gained media attention in 2019 tended to engage in overt campaign advocacy and therefore did not seek to exploit ambiguities in the definition of election spending. The high threshold for registration is more likely to explain why much digital activity may fall outside of the regulations. Most digital campaigners will not come close to spending the necessary $£ 10,000$ or $£ 20,000$ that triggers the requirement to register. That threshold was set as a way to prevent administrative burdens being imposed on relatively small organisations. The threshold is also 
connected to the definition of electoral activity discussed above. For example, a third party may engage in various political activities, some electoral and others not. The third party may then be able to split certain costs between the electoral and non-electoral activities, which could further reduce the level of expenditures counting towards the threshold for registration.

That an organisation spends below the threshold for registration does not eliminate all concerns about money. The ease with which a third party organisation can be established and advertise means that it would be possible for multiple electoral advocacy groups to be established, all promoting the same party or candidate. One such group may cover immigration, while another may cover tax issues, and so on, with no coordination. The spending of each group may fall below the threshold for registration, but in the aggregate the activities could have a significant effect on the campaign debate. Moreover, as such low spending groups fall outside the regulations, there would be nothing to stop the same person donating significant sums to each of those groups without disclosure, or for such groups to be financed by a person outside the UK.

The concern is not just with money. The system of third party registration allows for a level of transparency. Where the spending falls below the threshold, there will be no need to register with the Electoral Commission or disclose the sources of funding. Information about such organisations may be more important than ever, given that the public may have little basis on which to assess the credibility of the messages. Lowering the threshold for registration would bring more organisations into the regulatory regime and provide greater transparency about such organisations. However, such a reform would be likely to suffer some backlash insofar as it would have a chilling effect on independent campaigners. An alternative strategy might be to have more limited obligations on organisations spending at a lower threshold, which could include providing information about who is behind an organisation and the major sources of funding.
One proposal along such lines is to extend the 'imprint' requirements-which require printed election material to include details of the publisher (or the person who it is published on behalf of) - to digital media. There have been longstanding calls for such a change, and it would provide for a basic tier of regulation applicable to low spending campaigns. However, the effectiveness of the measure would depend on the type of communication the requirement is applicable to (for example, whether it applies only to paid advertising). Another strategy is to place responsibility on the digital platforms to verify the identity of and provide greater information about political and electoral advertisers. The large platforms, including Google and Facebook, voluntarily adopted such measures prior to the 2019 election, including a publicly accessible archive of political advertisements. Those measures were significant, both in allowing targeted third party advertising to be visible to the public at large, and in providing some information about the spending and advertiser. That information has also assisted regulators, by providing an indication of those organisations that are approaching the threshold for registration.

There are limits to such voluntary measures undertaken by the technology companies. For example, different platforms have differing definitions of political advertising, so the data provided by the various companies are not directly comparable. There are also limits to the information provided. For example, archives do not indicate whether the spending was targeted in a particular constituency, which can make it harder to check if the specific spending limits under the PPERA were being complied with. In 2019, media reports also queried whether the technology companies' rules on disclosure were being enforced. ${ }^{15}$ Securing transparency should not be left to the companies to devise on their own terms. The disclosure of political advertising should be a regulatory requirement and is likely to be included in forthcoming legislation regulating digital platforms.

Even with more stringent and consistent regulation of the digital platforms, there are limits as to the information the technology companies can provide. A platform for 
digital advertising will not know the sums spent on production or the research that went into an advertisement. There are other types of digital advertising that are unknown to the platforms, for example where a campaigner pays an influencer to carry a certain message. That is connected to a broader point, that advertising is not the only form of political communication that campaigners can spend money on. With the limited information available and the numerous channels for communication, the full range of spending on third party activity is not known.

The discussion earlier noted that third party controls were often seen to provide a way to prevent avoidance of the rules applicable to political parties. That meant the rules applicable to third parties (registration, transparency of funding and spending limits) were designed through an analogy with party funding laws. As third party activity on the digital media grows in importance, it is likely to raise distinct issues that are not simply about making party funding laws workable. Unlike a major political party, a third party engaging in electoral activity may have no prior public profile or reputation, and have no ongoing relationship with the public. The organisation could be set up for a short period, only to disappear after an election. Such an organisation will not be subject to the informal reputational constraints that candidates and parties are subject to. A largely unknown group can get away with saying many things that a party representative cannot (or at least should not) get away with. The potential to engage in unfair personalised attacks, disingenuous appeals, and false statements, may be much greater. As a result, some third party activities have the potential to change the tone of the campaign debate.

A growth in third party activity may, therefore, bring questions of campaign ethics to the fore. The solutions to some issues will fall outside election law, and may fall to separate lobbying regulations, for example, to reveal who is behind an 'astroturf campaign'. Other problems may not have an obvious regulatory solution and are possibly better addressed through measures to support an ecosystem of information in which the media and other organisations challenge misleading statements and provide a forum for reasoned debate.

\section{Conclusion}

The discussion has shown how third parties have long been subject to some regulation in relation to election campaigning. For much of the twentieth century the laws were simultaneously out of date in relation to campaigns in support of parties, while excessively strict in relation to candidate supporting campaigns. While those defects have been addressed, the regulation has grown increasingly complex, as it has been subject to piecemeal reforms that add new layers of control. That complex system has proven difficult for large campaign organisations to navigate, and can pose a challenge to smaller third parties. The official figures on third party activity show a relatively small number of organisations spending significant sums on electoral activity. However, such statistics do not provide a complete picture. Some level of activity will fall outside the radar of election law, insofar as it does not meet the threshold for registration, does not engage in electoral activity (but does engage in political advocacy), and where the full extent of spending is not known to regulators.

Despite the limited figures, the activities of some campaigners became prominent in the 2019 election, owing to increased disclosure on the digital platforms. In light of concerns about shadow campaigns, an obvious response is to demand that laws be tightened and extended. That, however, raises a difficult dilemma for law makers. A further extension of the law may risk restricting political debate and trigger a backlash - as highlighted in the response to the so-called 'gagging' amendments in 2014 or the Bowman decision. The potential for such perceived censorship is a particular risk with digital media, which is seen as a vehicle for citizen participation. As a result, it is important to be aware of potential chilling effects and other unintended consequences.

There is, however, a case for reforming election laws. The law could be clarified, so that campaigners do not have to navigate such complex tiers of regulation that have built up through piecemeal reforms. There are also ways of strengthening the powers of the Electoral Commission, to ensure that existing standards are complied with. While it appears that much digital activity is low 
cost, the limited information available means that it is difficult to assess the overall level of spending on digital campaigning (beyond formal advertising costs). To address that problem, the rules on transparency could be strengthened. The issues about third parties are not limited to concerns about spending and raise some broader ethical questions that are less easily addressed by election laws. While further research will be necessary to assess the levels of third party activity, the use of the digital media means that official party campaigns now run alongside multiple unofficial micro-campaigns run by third parties. Such activity looks likely to be a growth area and the third party activity that received attention in 2019 may be a taste of what is to come in future elections.

\section{Notes}

1 For example, see 'Shadow campaigners' digital ad blitz leaves voters blind to party affiliations', Financial Times, 7 December 2019; 'Voters hoodwinked in online guerrilla war', Times, 3 December 2019; 'Brexit donor and lobbyist among those funding "shadow campaigns", Times, 20 November 2019.

2 Electoral Commission, UK Parliamentary General Election 2015: Campaign Spending Report, 2016, p. 36.

3 Committee on Standards in Public Life, The Funding of Political Parties, Cm 4057, 1998, [10.72].

4 Bowman v UK, 1998, 26 EHRR 1, [45]-[47].

$5 R v$ Tronoh Mines, 1951, 35 Cr App R 19.

6 If the third party runs separate campaigns in all four nations, then the maximum spend is $£ 465,300$.
$7 £ 31,980$ in England, £3,540 in Scotland, £2,400 in Wales and $£ 1,080$ in Northern Ireland.

8 Lord Hodgson, Third Party Election Campaigning-Getting the Balance Right, Cm 9205, 2016, [6.20].

9 Ibid., [6.35].

10 Committee on Standards in Public Life, Political Party Finance, Cm 8208, 2011, p. 40.

11 Electoral Commission, 'General election spending returns for larger parties published', 19 March 2018; https://www.electoralcommis sion.org.uk/general-election-spending-returnslarger-parties-published (accessed 30 July 2020).

12 Electoral Commission, 'Party and non-party campaigner spending of $£ 250 \mathrm{k}$ or less at 2019 general election', 18 June 2020; https:/ /www.e lectoralcommission.org.uk/media-centre/partyand-non-party-campaigner-spending-ps250k-orless-2019-general-election (accessed 30 July 2020).

13 The 2014 amendments lowered spending limits, but raised the threshold for registration.

14 The full test also applies to spending reasonably regarded as intended to promote 'one or more registered parties who advocate (or do not advocate) particular policies or who otherwise fall within a particular category of such parties', or 'candidates who hold (or do not hold) particular opinions or who advocate (or do not advocate) particular policies or who otherwise fall within a particular category of candidates'. Under Schedule 8A of the PPERA, the regulations apply to spending on publications, canvassing, market research, media events, transport and public rallies.

15 See Sky News, 'Google breaches own rules with undisclosed Tory attack ad', 21 November 2019; https://news.sky.com/story/googlebreaches-own-rules-with-undisclosed-tory-attac k-ad-11866416 (accessed 30 July 2020). 